\title{
Editorial: Developments in southern hemisphere paleoclimate research
}

Peter Kershaw ${ }^{1}$ and Jérôme Chappellaz ${ }^{2}$

1School of Geography and Environmental Science, Monash University, Australia; peter.kershaw@arts.monash.edu.au Laboratoire de Glaciologie et Géophysique de l'Environment, Domaine Universitaire, France; jerome@lgge.obs.ujf-grenoble.fr

The newsletter cover nicely symbolizes the general perception of poor knowledge about the southern hemisphere, which extends into the paleoclimatic realm. Certainly, the tradition of Quaternary research stems from the northern hemisphere and a sustained focus is justified by the dominant role of the North Atlantic region in modulating climate change. The establishment of the PAGES Pole-Equator-Pole (PEP) transects led to a major impetus in the integration of information from southern and northern continents, and further highlighted the geographical separation of southern landmasses. One attempt to provide a southern focus was the INQUA and PAGES inspired 'Paleoclimates of the Southern Hemisphere' (PASH) program, but it succumbed to the tyranny of distance.

The increasing recognition over the last few years of the necessity for a global synthesis in order to refine climate change modelstogether with an acknowledgement that southern and low-latitude climate mechanisms had a much greater impact on paleoclimate than previously realized (e.g., with the specific presence of a huge ice sheet, surrounded by an ocean playing a key role in redistributing energy and carbon) - has provided a boost to Antipodean project formulation and execution*. But the picture still remains far from the spatial and temporal coverage of its northern counterpart.

This newsletter issue focuses on some science highlights and news articles, which are predominantly linked with these Antipodean projects, and covers all major southern landmasses and the Southern Ocean. Antarctica and its archives have proved a trigger for southern hemisphere research by providing insights into, for example, the polar 'see-saw', the mid-Bruhnes transition-through evidence of a switch to more pronounced interglacials_and the full temporal extent of the current ice-age (the last ca. 35 Myr). Contributions relating to Antarctica in this issue derive from such projects as those within IPICS (International Partnerships in Ice Core Sciences), SCAR (Scientific Committee on Antarctic Research) and ACE (Antarctic Climate Evolution), and extend the main timescale of PAGES interest, in recognition of the need to understand the mechanisms at work, under boundary conditions slightly different to those of today. Several articles relate to the INQUA Paleoclimate Commission (PALCOMM) project on Land-Ocean Correlation of Long Records from the Southern Hemisphere on Orbital and Suborbital Timescales. This is essentially a revamped PASH initiative, with a more integrated structure. In comparison with the oceans, long terrestrial sediment cores have been difficult to recover, however, projects formulated in association with the International Continental Drilling Program, two of which are featured here, are beginning to have a big impact in establishing regional relationships with both high- and low-latitude forcing. Highlighted also are details of the Pleistocene/Holocene transition or Termination I, with the record from Australasia formally incorporated into an Australasian INTIMATE project. This project examines the degree of hemispheric synchroneity between this Pacific region and the North Atlantic, under the parent INTIMATE project. Three contributions herald a new PAGES initiative directed towards the high-resolution reconstruction of past climatic variations and their modeling on a regional basis over the late Holocene, following on from the European LOTRED (Long Term Climate Reconstruction and Dynamics) project. LOTRED-South America was launched at a meeting in Mendoza, Argentina in 2006 and the first outcome, a special issue of Palaeogeography, Palaeoclimatology, Palaeoecology will be published in early 2008. Moves have been made to set up an Australasian-LOTRED, and to further expand the network with the group CACHE-PEP, which focuses on the region from southernmost South America to the Antarctic Peninsula.

Overall, we hope that this issue of the PAGES newsletter will increase the awareness that the southern hemisphere must not be underestimated in global change studies, and that long-term efforts are still required to better document its evolution.

* Success of the various projects is dependent on data availability. Contributors are encouraged to lodge their data with the World Data Centre for Paleoclimatology (www.ncdc.noaa.gov/paleo/data.html) or PANGEA (www.wdc-mare.org).

\section{**Acronym Database**}

For clarification of acronyms used in this editorial and articles in this newsletter, and links to the websites of the above-mentioned programs, please visit the PAGES-related acronym website: www.pages-igbp.org/about/abbreviations.html

\section{PAGES Calendar 2007/08}

14 - 25 January, 2008 - Dichato Concepcion, Chile Austral Summer Institute VIII

www2.udec.cl/oceanoudec/oceanografia/

\author{
26 - 29 May, 2008 - Louvain-la-Neuve, Belgium \\ Slow dynamics of climate change \\ www.uclouvain.be/berger2008
}

\author{
05 - 09 May, 2008 - Cape Town, South Africa \\ 4th IGBP Congress: Sustainable livelihoods in a \\ changing Earth system \\ www.igbp2008.co.za/
}

11 - 14 June, 2008 - Lääne-Virumaa, Estonia Peatland archives of Holocene climate variability www.pages-igbp.org/calendar/calendar08.html

\author{
29 June - 03 July, 2008 - Alaska, USA \\ International Conference on Permafrost \\ www.nicop.org/
}

\author{
11 - 13 August - Shanghai, China \\ Quaternary pollen database of China \\ www.pages-igbp.org/calendar/calendar08.html
}

